\title{
Mental health care use in medically unexplained and explained physical symptoms: findings from a general population study
}

This article was published in the following Dove Press journal:

Neuropsychiatric Disease and Treatment

16 August 2016

Number of times this article has been viewed

Jonna F van Eck van der Sluijs, ${ }^{1,2}$ Margreet ten Have, ${ }^{3}$

Cees A Rijnders, ${ }^{4}$ Harm WJ van Marwijk, ${ }^{5,6}$ Ron de Graaf, ${ }^{3}$ Christina M van der Feltz-Cornelis ${ }^{1,2}$

'Clinical Centre of Excellence for Body, Mind and Health, GGz Breburg, ${ }^{2}$ Tranzo Department, Tilburg University, Tilburg, ${ }^{3}$ Netherlands Institute of Mental Health and Addiction, Utrecht, ${ }^{4}$ Department of Residency training, GGz Breburg, Tilburg, the Netherlands; ${ }^{5}$ Centre for Primary Care, Institute of Population Health, University of Manchester, Manchester, UK; ${ }^{6}$ Department of General Practice and Elderly Care Medicine, EMGO Institute for Health and Care Research, VU University Medical Centre, Amsterdam, the Netherlands

\section{Video abstract}

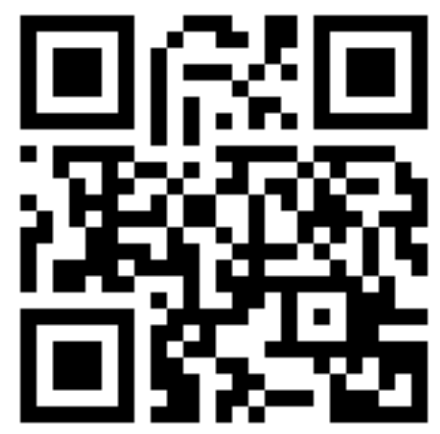

Point your SmartPhone at the code above. If you have a QR code reader the video abstract will appear. Or use: http://youtu.be/-kzbGFmaiA0

Correspondence: Jonna F van Eck van der Sluijs Clinical Centre of Excellence for Body, Mind and Health, GGz Breburg, Postbus 770, 5000AT Tilburg, the Netherlands Email j.vaneckvandersluijs@ggzbreburg.nl
Objective: The aim of this study was to explore mental health care utilization patterns in primary and specialized mental health care of people with unexplained or explained physical symptoms.

Methods: Data were derived from the first wave of the Netherlands Mental Health Survey and Incidence Study-2, a nationally representative face-to-face cohort study among the general population aged 18-64 years. We selected subjects with medically unexplained symptoms (MUS) only (MUSonly; $\mathrm{n}=177$ ), explained physical symptoms only (PHYonly, $\mathrm{n}=1,952$ ), combined MUS and explained physical symptoms (MUS + PHY, n=209), and controls without physical symptoms (NONE, $n=4,168$ ). We studied entry into mental health care and the number of treatment contacts for mental problems, in both primary care and specialized mental health care. Analyses were adjusted for sociodemographic characteristics and presence of any 12-month mental disorder assessed with the Composite International Diagnostic Interview 3.0.

Results: At the primary care level, all three groups of subjects with physical symptoms showed entry into care for mental health problems significantly more often than controls. The adjusted odds ratios were $2.29(1.33,3.95)$ for MUSonly, $1.55(1.13,2.12)$ for PHYonly, and 2.25 $(1.41,3.57)$ for MUS + PHY. At the specialized mental health care level, this was the case only for MUSonly subjects (adjusted odds ratio 1.65 [1.04, 2.61]). In both the primary and specialized mental health care, there were no significant differences between the four groups in the number of treatment contacts once they entered into treatment.

Conclusion: All sorts of physical symptoms, unexplained as well as explained, were associated with significant higher entry into primary care for mental problems. In specialized mental health care, this was true only for MUSonly. No differences were found in the number of treatment contacts. This warrants further research aimed at the content of the treatment contacts.

Keywords: medically unexplained symptoms, explained physical symptoms, mental health care use, general population

\section{Introduction}

\section{Background and rationale}

Little is known about how physical symptoms impact mental health care use. Physical symptoms can either be explained, in the context of a somatic illness, or lack such an explanation. Medically unexplained symptoms (MUS) are defined as physical symptoms where a physician cannot find a specific cause. ${ }^{1}$ People with MUS are known to have comorbid mental disorders, such as mood and anxiety disorders, more often in comparison to healthy controls in the general population ${ }^{2}$ in primary and specialized care $^{3}$ and in tertiary care. ${ }^{4}$ This raises questions about the influence of MUS on mental 
health care use. Individuals with three or more concomitant physical symptoms, whether medically unexplained or not, have greater odds of having used mental health care services in the past year. ${ }^{5}$ However, it is not known whether this would be the same after adjustment for mental disorders and whether it has an impact on the number of treatment contacts. Entry into mental health care and the number of treatment contacts might be influenced by unsuccessful referrals in which patients who need referral do not reach mental health care. ${ }^{6}$

Opinions differ regarding the relative mental health care utilization pattern of people with MUS versus people with explained physical symptoms. Evidence suggests that the existence of comorbid somatic conditions increases the mental health care utilization in people with a common mental disorder; ${ }^{7}$ however, whether the existence of MUS also increases entry into mental health care is unknown. On the one hand, it may be assumed that people with MUS would seek treatment in specialized mental health care for their problems associated with MUS, because general practitioners (GPs) find it difficult to treat these problems. ${ }^{6}$ In that case, the complexity of the problems might lead to more treatment contacts. On the other hand, it has also been suggested that people with MUS attend somatic health care services frequently ${ }^{8}$ but would resist mental health care referral, ${ }^{9,10}$ as they would prefer to seek a somatic explanation for their physical symptoms, instead of getting mental health treatment. ${ }^{10}$ In addition, if in such a case a GP would succeed in referring the person to specialized mental health care; the offered treatment might not fit with the request of the patient, which might lead to an early ending of the therapy and consequently a low number of treatment appointments. Finally, the number of treatment contacts might be influenced both negatively and positively or even might show no overall differences in the number of treatment contacts due to conflicting influences.

It is not known whether the group of people with MUS in the general population is comparable to the "selected" groups of patients whose mental health care use patterns have been investigated. ${ }^{5-8,10,11}$ More insight into the mental health care use patterns of people with either MUS, explained physical symptoms, or both can give us clues about what is needed to optimize mental health care for these groups. The outcomes of this study inform us whether the focus of future research should be how to optimize entry into care or gaining more insight into the content and effects of delivered mental health care to people with concomitant physical symptoms. This warrants the current investigation in a psychiatric study with a large representative sample from the Dutch general population that has not been selected based on health care use, involving subjects with both unexplained and explained physical symptoms.

\section{Objective}

The objective was to explore how physical symptoms are associated with mental health care use in both primary and specialized mental health care. We therefore compare service use patterns for subjects with MUS only (MUSonly), with explained physical symptoms only (PHYonly), with both MUS and explained physical symptoms and for controls without symptoms, with respect to entry into mental health care and the number of treatment contacts once one has entered care. Based on the literature mentioned earlier, we hypothesize that subjects with both MUS and explained physical symptoms more often enter mental health care.

\section{Methods \\ Study design}

In this general population study, we examine mental health care use in terms of entry into primary and specialized mental health care, which is defined as at least one treatment contact. Furthermore, we examine the number of visits to mental health care. Subjects were divided into primary care only for mental problems and specialized mental health care (regardless of whether they also used primary care, comparable to earlier research). ${ }^{12}$ We report our findings according to the STrengthening the Reporting of OBservational studies in Epidemiology (STROBE) statement. ${ }^{13}$

\section{Setting and participants}

Data were derived from the first wave (2007-2009) of the Netherlands Mental Health Survey and Incidence Study-2 (NEMESIS-2). ${ }^{14,15}$ Methods of NEMESIS-2 are described elsewhere. ${ }^{14}$ Briefly, NEMESIS-2 is a nationally representative face-to-face population study including subjects aged 18-64 years at baseline. NEMESIS-2 was approved by the Medical Ethics Review Committee for Institutions on Mental Health Care (METIGG). After being informed about the study, subjects provided written informed consent.

NEMESIS-2 is based on a multistage, stratified random sampling of households, with one respondent aged 18-64 years randomly selected in each household for a face-to-face interview. The interviews were conducted by professional, experienced interviewers. The response rate was $65.1 \%$. The sample was nationally representative, although younger subjects were somewhat underrepresented. Of the total group of 6,646 baseline subjects, 140 subjects 
received a shortened version of the questionnaire, and as a consequence they did not receive questions about somatic disorders. Therefore, the number of subjects in the current analyses was 6,506 .

\section{Variables}

\section{Service use}

We examined 12-month mental health care use separately for two health care sectors: primary care and specialized mental health care. Within these sectors, we examined two stages of the care process: entry into mental health care (defined as the presence of any mental health contact) and, after entry into care, the number of mental health care visits. This is comparable to earlier research designs. ${ }^{12}$

The primary care sector included GPs, company doctors, social workers, home care or district nurses, physiotherapists or haptonomists, medical specialists, and other professionals working within the general medical care sector. As described in an earlier article, ${ }^{7}$ the primary care setting is the original point of service entry in the Netherlands. Patients need referral of their GP before they can go to a mental health practitioner. Common mental health disorders can be treated in the primary care setting by the abovementioned primary care practitioners. When a mental disorder is chronic, more severe, or complex, patients can be referred by the GP to a specialist mental health treatment setting. The specialized mental health care sector included psychiatrists, psychologists, psychotherapists, and part-time or full-time psychiatric treatment.

\section{Definition of MUS}

For this study, we use the following definition of MUS: presence of one or more physical symptom(s) in the past 12 months for which no adequate organ pathology or pathophysiological basis was found, and for which, according to the subject, a physician was consulted and/or medication was received, and which caused discomfort and functional impairment in the past 4 weeks as measured by the physical health subscales of the Short Form 36..$^{1,16-18}$ We included the presence of discomfort and functional impairment in the definition, to stay in line with the Somatoform disorders in Diagnostic and Statistical Manual of Mental Disorders, fourth edition, text revision (DSM-IV-TR) ${ }^{19}$ and the DSM-V somatic symptom disorder (SSD), ${ }^{20}$ in which both require discomfort and functional impairment.

\section{Data sources and measurement}

For MUS, explained physical symptoms, and mental disorders, measures were used as described in Table 1 (which was also published in our previous study). ${ }^{2}$

\section{Bias}

We made the following efforts to address potential sources of bias. As we expect the presence of a mental disorder to influence service use, analyses were adjusted for the presence of any 12-month mental disorder. These mental disorders were assessed with the Composite International Diagnostic Interview (CIDI) 3.0 and are described in Table 1 (mood, anxiety, and substance use disorders). We also adjusted the analyses for sociodemographics. Furthermore, a strict definition for the self-report of physical symptoms was used: subjects had to have visited or be treated by a physician or use prescribed medication, for the particular physical symptom to be seen as present.

\section{Quantitative variables and study size Operationalization of four groups}

The following groups were distinguished: first, those who had MUS, but no physical symptoms that could be explained by physical disorders, were grouped as "MUSonly" $(n=177)$. Second, subjects with explained PHYonly, which were the physical symptoms in the checklist minus those symptoms that were considered to be MUS, were grouped as "PHYonly" $(n=1,952)$. Third, those who had both MUS and explained physical symptoms were grouped as "MUS + PHY" (n=209). The control group included subjects with no MUS and no explained physical symptoms ("NONE", n=4,168).

\section{Statistical methods}

All analyses were performed with STATA Version 12.1, using weighted data to correct for differences in the response rates of several sociodemographic groups, and differences in the probability of the selection of subjects within households. In our analyses, we defined the complex sampling and recruitment procedure of the study in order to correct for possible clustering in the data resulting in robust standard errors (SEs). ${ }^{35}$

Summary statistics (ie, tables of frequencies) were used to describe the sociodemographic characteristics of the abovementioned four groups of subjects, MUSonly, PHYonly, MUS + PHY, and NONE (Table 2).

In Table 3, entry into care for mental health problems among the four groups is described in percentages and odds ratios (ORs). To investigate whether group membership played an independent role in explaining service use, logistic regression analyses were performed, controlling for sociodemographic characteristics (sex, age, living situation, education, and employment situation; model 1) and also for any 12-month mental disorder (model 2). In these analyses, the group NONE was used as the reference group. In Table 4, 
Table I Measures

Measurement
Medically unexplained physical symptoms
Subjects were considered to have MUS if their condition applied to
both criteria mentioned below
I. Presence of one of the following physical symptoms, experienced
in the past I 2 months, for which the subjects indicated that they
visited a physician or received medication:
a) Disturbing intestinal symptoms, existing longer than 3 months, for
which no indication of an explanation existed ${ }^{21-23}$
b) Back problems existing longer than 3 months, for which no
indication of an explanation existed ${ }^{22,24}$
c) Other illness or physical symptoms that are long lasting (open
question) and unexplained

2. Presence of limited functioning reported in the past 4 weeks, as indicated by two or more of the physical health subscales of the SF-36 17,18

\section{Explained physical symptoms}

Respiratory disorders (asthma, chronic obstructive pulmonary disease, chronic bronchitis, emphysema), cardiovascular disorders (severe heart disease, heart attack, hypertension, stroke), stomach or intestinal ulcers, severe intestinal symptoms (only if an explanation about the cause was given such as pancreatitis, hernia abdominalis), diabetes, thyroid disorder, chronic back pain (only if an explanation about the cause was given such as neck hernia, paraplegia, caused by accident), arthritis, migraine, cancer, impaired vision, or hearing

Covariate: DSM-IV mental disorders

DSM-IV mood disorder (major depression, dysthymia, bipolar disorder), anxiety disorder (panic disorder, agoraphobia [without panic disorder], social phobia, specific phobia, generalized anxiety disorder) and substance use disorder (alcohol/drug abuse and dependence). In this article, we combined the 12-month mood, anxiety, and substance use disorders, to form the group "any 12-month mental disorder"

\section{Measuring instrument}

Interview based on questionnaire of physical symptoms

All physical symptoms mentioned here (verbatim responses) were checked independently by two physicians (Jonna van Eck van der Sluijs and Christina van der Feltz-Cornelis) to indicate whether or not they could be considered medically unexplained physical symptoms in general. If their judgments were not the same, they deliberated until consensus was achieved

We checked the answers on the open questions to see if an explanation was given about the intestinal symptoms, such as pancreatitis or hernia abdominalis, or the back problem, such as neck hernia or paraplegia

If this was the case, we did not include the subject in the unexplained group, but in the explained group

Examples of general symptoms that we considered to be medically unexplained physical symptoms are fibromyalgia, fatigue (such as chronic fatigue syndrome), pain without medical explanation (such as stress-related pain in muscles), and physical symptoms accompanied with phrases such as "they cannot find anything" or "if only I knew" Interview based on SF-36 physical health subscales:

a) Physical functioning: some or severe limitations in at least one of the ten items in this category

b) Physical role functioning: any limitation reported in at least one of the four items in this category

c) Bodily pain: pain leading to any limitation in normal work activities

d) General health: describes mental or physical health as poor, and/or negative expectations about one's health

Interview based on questionnaire of physical symptoms, in which the main physical symptoms of the CBS (Netherlands Central Bureau of Statistics) questionnaire can be found..$^{25}$ These physical symptoms were based on self-report by the subjects during the interview, and not by medical records. ${ }^{26}$ Comparisons between self-reports of chronic physical disorders and medical records show moderate-to-good concordance. ${ }^{27-29}$ Subjects were considered to have physical symptoms if they reported to have been treated or monitored by a physician in the prior 12 months for one or more of the disorders, and after confirmation by two physicians, in duplicate, that symptoms were considered to be medically explained CIDI 3.026,30,31

Interviews were conducted by professional, experienced interviewers. Clinical calibration studies conducted in various countries have found that CIDI $3.0^{32}$ and earlier versions $\mathrm{s}^{33,34}$ assess anxiety and mood and substance use disorders with generally good validity compared to blinded clinical reappraisal interviews

Abbreviations: CIDI, Composite International Diagnostic Interview Version 3.0; DSM-IV, Diagnostic and Statistical Manual of Mental Disorders, fourth edition; MUS, medically unexplained symptoms; SF-36, Short Form 36.

the number of treatment contacts after entry into care among the four groups is described in means and incidence rate ratios. To investigate whether group membership played an independent role in explaining the number of mental health visits made after entry into care, multiple negative binomial regression analyses were performed, ${ }^{12}$ controlling for confounders variables (for sociodemographic characteristics in model 1 and also for any 12-month mental disorder in model 2). Again, in these analyses, the group NONE was used as reference group. All analyses were performed with complete data of the 6,506 subjects, so there were no missing data. 
Table 2 Sociodemographic characteristics and mental health status of subjects with and without MUS and explained physical symptoms $(\mathrm{N}=6,506)$, in unweighted numbers and weighted column percentages

\begin{tabular}{|c|c|c|c|c|c|c|}
\hline & $\mathbf{n}$ & $\begin{array}{l}\text { MUSonly } \\
(n=\mid 77)(\%)\end{array}$ & $\begin{array}{l}\text { PHYonly } \\
(n=1,952)(\%)\end{array}$ & $\begin{array}{l}\text { MUS + PHY } \\
(n=209)(\%)\end{array}$ & $\begin{array}{l}\text { NONE } \\
(n=4,168)(\%)\end{array}$ & $P$-value \\
\hline \multicolumn{7}{|l|}{ Sex } \\
\hline Female & 3,589 & 60.4 & 55.9 & 67.2 & 45.4 & $<0.000$ I \\
\hline \multicolumn{7}{|l|}{ Partner status } \\
\hline With partner & 4,419 & 65.5 & 71.6 & 73.9 & 65.3 & 0.0003 \\
\hline \multicolumn{7}{|l|}{ Age (years) } \\
\hline $18-24$ & 477 & 7.3 & 8.2 & $\mathrm{I} .4$ & 15.3 & \\
\hline $25-34$ & 1,100 & 18.3 & 11.8 & 7.8 & 23.6 & \\
\hline $35-44$ & 1,659 & 28.7 & 20.2 & 19.4 & 26.5 & \\
\hline $45-54$ & 1,559 & 28.1 & 27.6 & 33.1 & 20.4 & \\
\hline $55-64$ & I,7II & 17.7 & 32.2 & 38.4 & 14.1 & $<0.000$ I \\
\hline \multicolumn{7}{|l|}{ Employment situation } \\
\hline With paid job & 4,858 & 65.0 & 71.3 & 50.3 & 80.3 & $<0.000$ I \\
\hline \multicolumn{7}{|l|}{ Education } \\
\hline Primary, basic vocational & 312 & 6.0 & 10.1 & 13.3 & 5.5 & \\
\hline Lower secondary & ।,782 & 22.5 & 22.8 & 27.4 & 22.3 & \\
\hline Higher secondary & 2,095 & 46.4 & 42.4 & 41.2 & 41.2 & \\
\hline Higher professional, university & 2,317 & 25.2 & 24.7 & 18.1 & 31.0 & $<0.000$ I \\
\hline Any I2-month mental disorder & 1,090 & 30.5 & 20.0 & 28.8 & 15.4 & $<0.0001$ \\
\hline
\end{tabular}

Abbreviations: MUS, medically unexplained symptoms; MUSonly, MUS, no explained physical symptoms; PHYonly, explained physical symptoms, no MUS; MUS + PHY, both MUS and explained physical symptoms; NONE, no explained physical symptoms, no MUS; $P, P$-values are related to the differences in sociodemographics between the four groups, not on a specific comparison.

Table 3 Entry into care for mental health problems among subjects with and without MUS and explained physical symptoms (N=6,506), in unweighted numbers, weighted column percentages, and weighted adjusted ORs with $95 \% \mathrm{Cl}$

\begin{tabular}{|c|c|c|c|c|c|c|c|c|}
\hline \multirow{3}{*}{$\begin{array}{l}\text { Type of physical } \\
\text { symptoms }\end{array}$} & \multicolumn{4}{|c|}{ Primary care only } & \multicolumn{4}{|c|}{ Specialized mental health care } \\
\hline & \multirow[t]{2}{*}{$\mathbf{n}$} & \multirow[t]{2}{*}{$\%$} & \multirow{2}{*}{$\frac{\text { Model I }}{\text { OR }(95 \% \mathrm{CI})}$} & \multirow{2}{*}{$\frac{\text { Model } 2}{\text { OR }(95 \% \mathrm{CI})}$} & \multirow[t]{2}{*}{$\mathbf{n}$} & \multirow[t]{2}{*}{$\%$} & \multirow{2}{*}{$\frac{\text { Model I }}{\text { OR }(95 \% \mathrm{CI})}$} & \multirow{2}{*}{$\frac{\text { Model } 2}{\text { OR }(95 \% \mathrm{CI})}$} \\
\hline & & & & & & & & \\
\hline MUSonly (n=177) & 16 & 10.5 & $2.89(1.71,4.90)$ & $2.29(1.33,3.95)$ & 29 & 14.4 & $2.40(1.47,3.92)$ & $1.65(1.04,2.6 I)$ \\
\hline PHYonly $(n=I, 952)$ & 117 & 5.9 & $1.74(1.26,2.43)$ & $1.55(1.13,2.12)$ & 136 & 6.6 & $1.22(0.93,1.61)$ & $1.00(0.75,1.33)$ \\
\hline MUS + PHY (n=209) & 21 & 9.8 & $2.89(1.82,4.60)$ & $2.25(1.41,3.57)$ & 26 & 10.4 & $1.58(0.90,2.77)$ & $1.07(0.62,1.83)$ \\
\hline NONE $(n=4,168)$ & 163 & 3.5 & Ref & Ref & 240 & 5.5 & Ref & Ref \\
\hline
\end{tabular}

Notes: Bold values represent significant OR at the 0.05 level, two-sided test. Model I: adjusted for sociodemographic characteristics (sex, age, living situation, employment situation, and education). Model 2: adjusted for sociodemographic characteristics (sex, age, living situation, employment situation, and education) and any I2-month mental disorder.

Abbreviations: $\mathrm{Cl}$, confidence interval; MUS, medically unexplained symptoms; OR, odds ratio; MUSonly, MUS, no explained physical symptoms; PHYonly, explained physical symptoms, no MUS; MUS + PHY, both MUS and explained physical symptoms; NONE, no explained physical symptoms, no MUS; Ref, reference category.

Table 4 Number of treatment contacts for mental health problems among those using primary care only for mental health problems $(n=3 \mid 7)$ and among those using specialized mental health care $(n=43 I)$, in unweighted numbers, mean, and weighted adjusted IRR with $95 \% \mathrm{Cl}$

\begin{tabular}{|c|c|c|c|c|c|c|c|c|}
\hline \multirow{3}{*}{$\begin{array}{l}\text { Type of } \\
\text { physical } \\
\text { symptoms }\end{array}$} & \multicolumn{4}{|c|}{$\begin{array}{l}\text { Number of treatment contacts for mental health care } \\
\text { (in primary care) }\end{array}$} & \multicolumn{4}{|c|}{$\begin{array}{l}\text { Number of treatment contacts (in specialized mental } \\
\text { health care) }\end{array}$} \\
\hline & \multirow[t]{2}{*}{$\mathbf{n}$} & \multirow{2}{*}{$\begin{array}{l}\text { Mean } \\
\text { (SE) }\end{array}$} & \multirow{2}{*}{$\frac{\text { Model I }}{\text { IRR (95\% CI) }}$} & \multirow{2}{*}{$\frac{\text { Model } 2}{\text { IRR }(95 \% \mathrm{CI})}$} & \multirow[t]{2}{*}{$\mathbf{n}$} & \multirow{2}{*}{$\begin{array}{l}\text { Mean } \\
(\mathrm{SE})\end{array}$} & \multirow{2}{*}{$\frac{\text { Model I }}{\text { IRR (95\% CI) }}$} & \multirow{2}{*}{$\begin{array}{l}\text { Model } 2 \\
\text { IRR }(95 \% \mathrm{CI})\end{array}$} \\
\hline & & & & & & & & \\
\hline MUSonly & 16 & $4.7(2.0)$ & $0.76(0.38, \mid .5 I)$ & $0.79(0.4 \mathrm{I}, \mathrm{I} .52)$ & 29 & $19.4(4.3)$ & I.04 $(0.67,1.63)$ & $0.84(0.5 \mathrm{I}, \mathrm{I} .38)$ \\
\hline PHYonly & 117 & $5.8(1.1)$ & $1.24(0.82,1.86)$ & I.34 $(0.89,2.00)$ & 136 & $13.0(1.8)$ & $0.73(0.50,1.07)$ & $0.69(0.46,1.03)$ \\
\hline MUS + PHY & 21 & $5.7(1.4)$ & I.29 (0.6I, 2.7I) & I.38 $(0.68,2.80)$ & 26 & $19.7(9.9)$ & I.24 (0.4I, 3.77) & I.3I $(0.39,4.43)$ \\
\hline NONE & 163 & $5.1(1.0)$ & Ref & Ref & 240 & $19.2(3.1)$ & Ref & Ref \\
\hline
\end{tabular}

Notes: Model I: adjusted for sociodemographic characteristics (sex, age, living situation, employment situation, and education). Model 2: adjusted for sociodemographic characteristics (sex, age, living situation, employment situation, and education) and any 12-month mental disorder.

Abbreviations: $\mathrm{Cl}$, confidence interval; IRR, incidence rate ratio; MUS, medically unexplained symptoms; SE, standard error; MUSonly, MUS, no explained physical symptoms; PHYonly, explained physical symptoms, no MUS; MUS + PHY, both MUS and explained physical symptoms; NONE, no explained physical symptoms, no MUS; Ref, reference category. 


\section{Results}

\section{Participants}

Table 2 describes the sociodemographic characteristics of the four groups: MUSonly, explained PHYonly, both MUS and explained physical symptoms (MUS + PHY), and healthy controls (NONE). The sociodemographic characteristics of our sample, with the exception of the presence of any 12-month mental disorder, were also described in our earlier article. $^{2}$

\section{Descriptive data}

There were significant differences between the groups regarding the following sociodemographic variables: women more often had physical symptoms than men, irrespective of whether the symptoms were explained, unexplained or both. Although the majority had a partner, subjects in the MUS only group and in the NONE group more often were single than subjects in the PHYonly group and in the MUS + PHY group. Both groups with explained symptoms had significantly more subjects in the higher age groups (55-64 years) than MUSonly and NONE. The employment rate in the MUS + PHY group was only $50.3 \%$, while $80.3 \%$ of people in the control group had a paid job. Approximately $25 \%$ in both the MUSonly and PHYonly groups had a higher professional/ university education versus $18.1 \%$ in the MUS + PHY group and $31.0 \%$ of the NONE group. Any 12 -month mental disorder was most prevalent in the MUSonly group.

\section{Outcome data and main results}

\section{Mental health care use}

The findings regarding entry into care are shown in Table 3. In the past 12 months, for mental health problems, $4.5 \%$ of the overall sample of 6,506 people used primary care only and $6.2 \%$ of the overall sample used specialized mental health care (not presented in Table 3). For mental health problems, MUSonly, PHYonly, and MUS + PHY groups used primary care more often compared to the control group. The adjusted ORs for MUSonly and MUS + PHY were the highest and almost equal; the OR for PHYonly was lower. After adjustment for sociodemographic characteristics and the presence of any 12-month mental disorder, the ORs for MUSonly and MUS + PHY were $\sim 2.3$ and for PHYonly 1.55.

The MUSonly group used specialized mental health care significantly more often compared to NONE. The OR adjusted for sociodemographic characteristics and the presence of any 12-month mental disorder was 1.65 . For the PHYonly and MUS + PHY groups, no significant differences were found, when compared to NONE.

\section{Number of treatment contacts}

Table 4 shows the number of treatment contacts among those using health care for mental problems. Overall, the mean number of contacts in the past 12 months among those using primary mental health care only and specialized mental health care is $5.4(\mathrm{SE}=0.6)$ and $17.4(\mathrm{SE}=2.0)$, respectively. In both primary care and specialized mental health care, there were no significant differences in the number of treatment contacts between the MUSonly, PHYonly, and MUS + PHY groups compared to the NONE group.

\section{Discussion}

\section{Key results}

A higher chance of entry into primary care for mental health problems was seen in people with physical symptoms irrespective of whether the symptoms were unexplained such as in MUS, explained by a chronic somatic condition, or a combination of the two - and also after adjustment for the presence of any mental disorder. All three categories of physical symptoms had a higher chance of entry into mental health care in the primary care setting. It is noteworthy that the category with the highest chance of entry into mental health care is the combined MUS + PHY category. It might well be the case that such a miscellaneous set of physical symptoms provides the subject with the highest need for mental health care. This is in line with previous findings that not only MUS but also explained physical symptoms are associated with mental disorder, and the higher the symptom count, the higher this association. Kroenke ${ }^{36}$ states that a higher somatic symptom count is a predictor of coexisting depressive or anxiety disorder. Recent stress, low selfrated health, high severity of the somatic symptom, and the clinician's perception that the patient encounter is difficult are other predictors of depression and anxiety. ${ }^{36}$ Escobar et $\mathrm{al}^{5}$ confirm that the number (three or more) of physical symptoms is more important than whether the symptoms are medically explained or not.

For subjects with MUS, entry into mental health care might be explained by their frequent dysfunctional cognitions (such as catastrophic thoughts) and feelings and behaviors regarding their physical symptoms (ie, fear of a serious physical disorder such as a heart attack leading to avoidance of exercise), which are reasons for consulting a physician for reassurance or treatment. These possible explanations could be explored in future research, for example, using the SSD-B Criteria Scale (SSD-12), a validated questionnaire assessing the aspects that are now used in the DSM-V as criterion $\mathrm{B} .{ }^{37}$ 
It should be noted that the label MUS covers a wide spectrum of conditions, and thus one could question whether the presence of MUS is the only reason for higher psychiatric morbidity, and thus need for mental health care, than healthy individuals. Nimnuan et $\mathrm{a}^{38}$ found that psychiatric morbidity per se was not associated with the presence of MUS in a hospital setting, but it was more likely in those with multiple symptoms. Another explanation may be that physical symptoms are misinterpreted symptoms of already existing mental disorders, ie, pain or weight loss in depression, muscle pain and fatigue in generalized anxiety disorder, and palpitations in panic disorder. ${ }^{20}$

In specialized mental health care, only subjects with MUS had an increased chance of at least one treatment contact after adjustment for the presence of any mental disorder. The availability of cognitive behavior treatment (CBT) for somatoform disorder might be of influence on this, given that it is a well-known treatment option. ${ }^{39-41} \mathrm{CBT}$ is recommended in the Dutch multidisciplinary guideline for MUS and somatoform disorders and can be offered by the GP or in the specialized mental health care, if the GP considers the patient to be too complex or when the patient-doctor relationship is perturbed. ${ }^{40}$ In addition to the CBT for MUS and somatoform disorder, specialist psychiatric attention may be required for other mental health problems associated with physical symptoms (unexplained or explained)., ${ }^{2,42}$ Given that all people with physical symptoms (explained or unexplained) show more entry into primary care, but only people with MUS show more entry into specialized mental health care, MUS is apparently of higher influence than explained physical symptoms on the decision of the GP whether or not to refer to specialized mental health care.

In model 2, entry into care and the number of treatment contacts were adjusted for the presence of any 12-month mental disorder, because that will be the main reason for asking and receiving mental health care. This article gives insight into the influence of the presence of physical symptoms (unexplained or explained) on the received mental health care. The difficulty is how we should view those physical symptoms: are they a parameter of the mental disorder or does the mental disorder influence the perceived severity of the physical disorders, or both? Winkler et $\mathrm{al}^{43}$ showed that in primary health care odds of having pain, hypertension, or diabetes mellitus are particularly elevated in people with co-occurring depressive and anxiety disorder. Especially for pain, it has been questioned whether there is a causal relationship with mental disorders, given the strong association between the two. ${ }^{44,45}$ In some individuals, the mental disorder may in fact be the primary and more serious condition; in others this may be the physical disorder. After entry into care, there were no significant differences in the number of treatment contacts between groups for both settings. After entry into primary mental health care, the mean number of treatment contacts is $\sim 5$ in all groups, which is the number of treatment sessions generally allotted to the general care psychologist. In specialized mental health care, the mean number of treatment contacts is between 13 and 20. This number of treatment contacts suggests that patients are not referred to specialized mental health care just to check if a mental disorder is present, but that they also receive treatment. It also suggests that people with MUS in the general population are not equal to selected patient groups with MUS. In those selected groups, GPs have difficulties treating the MUS-related problems ${ }^{6}$ and patients resist referral to specialized mental health care. ${ }^{9,10}$ In this general population study, people with MUS were referred more often to specialized mental health care and the number of treatment contacts did not differ when compared to people without physical symptoms, meaning we did not find indications for difficulties with referral or treatment. The exact content and results of this treatment are not known, however. Given the fact that depression as a risk factor for mortality is comparable to smoking, ${ }^{46}$ further research on the content and results of depression treatment is warranted: are the currently used treatments sufficient, or do people with combined physical and psychiatric complaints leave treatment insufficiently treated? Fear of stigmatization can also play a role in this by negatively influencing entry into care as well as the number of treatment contacts. ${ }^{47}$

Our first hypothesis is partly confirmed. We expected entry into care for mental health problems more often among subjects with MUS and/or explained physical symptoms. This was confirmed for primary care, but in specialized mental health care just for subjects with MUSonly. We did not have a specific expectation about the number of treatment contacts, because both an increase and a decrease could be hypothesized. This study showed that the number of treatment contacts did not differ between the four groups. Apparently, once an individual with physical symptoms has entered mental health care, his/her needs concerning the number of treatment contacts are the same if the physical symptoms are medically explained or unexplained symptoms.

\section{Strengths and limitations}

Important strengths of NEMESIS- 2 are the large representative study sample of the adult general population, and the 
use of a valid and reliable diagnostic instrument for mental disorders (CIDI 3.0). We combined the presence of one or more MUS with the presence of limited functioning, and thereby we approached the SSD as described in the DSM-V. ${ }^{20}$ As we used an existing database, we divided the sample into four groups based on predefined clinical criteria without being able to view medical records. Although we had this limitation, we believe that our methods of operationalization and classification are reasonable for MUS. Given that by definition the subjects in the MUS + PHY group had at least two physicals symptoms (one MUS and one PHY), the subjects in the MUSonly and in the PHYonly group at least one, and the subjects in NONE group no physical symptoms, we did not adjust our data for the number of physical symptoms.

Another limitation was that numbers became small in the various groups, but despite this we found significant differences for entry into care between the groups. Finally, for service use, and especially for the number of treatment contacts, recall problems might impact the respondents' estimations, but it is difficult to gauge the influence of this bias on the results of our study. Yet, it does appear unlikely that people with MUS or explained physical symptoms would systematically over- or underestimate their visits to mental health care services.

\section{Conclusion}

This is the first study exploring mental health care utilization patterns in subjects with MUS or explained physical symptoms at population level. The overall mental health care use was in line with what we expected: for mental problems, entry into primary care as well as into specialized health care use was seen more often in subjects with MUSonly compared to healthy controls. The same is true for entry into primary care for the combination of MUS and explained physical symptoms, and for explained PHYonly; for these groups entry into specialized mental health care did not differ significantly compared to people without physical symptoms. We learn from this that, despite the complexity and possibly strained patient-doctor relationships related to MUS, ${ }^{48}$ GPs do succeed in referring people with MUS to specialized mental health care. In both primary care and specialized mental health care, there were no significant differences in the number of treatment contacts between the groups. Based on this, we may conclude that in the general population, people with MUS are not as complex as selected groups of people with MUS. For health service planning, this means that similar services should be provided for people with MUS or medically explained physical symptoms. This service should focus on the burden experienced by the person regarding the physical symptoms and provide treatment for that, and this is in line with the new focus in the DSM-V on emotions, cognitions, and behavior regarding the physical symptoms, rather than the nature of the physical symptom, ie, whether it is explained or unexplained per se. Furthermore, the finding that the number of treatment contacts does not differ substantially in the case of concomitant mental disorders shows that the focus of treatment does not differ greatly in such cases. We also learn that further research about treatment options should focus on combined MUS and PHY rather than on unselected population-based samples.

Still to be researched is the course of MUS; in other words, do people with unexplained physical symptoms get better? ${ }^{49}$ Another question concerns what factors predict their prognosis. Further research could also focus on the content of the delivered care, the role of consultation, ${ }^{50,51}$ and the achieved results in terms of improvement of health and general functioning. As we only focused on the amount of care, further research could also study possible benefits of disease management programs for patients with both physical and mental disorders. ${ }^{52-55}$

\section{Generalizability}

NEMESIS-2 is a large, nationally representative sample of the adult Dutch general population. Therefore, the results can be extrapolated to the general population of the Netherlands. Whether findings are similar in other European countries or vary according to health care systems and welfare level should be the subject of further research.

\section{Acknowledgments}

NEMESIS-2 is conducted by the Netherlands Institute of Mental Health and Addiction (Trimbos Institute) in Utrecht. Financial support has been received from the Ministry of Health, Welfare and Sport, with supplementary support from the Netherlands Organization for Health Research and Development (ZonMw) and the Genetic Risk and Outcome of Psychosis (GROUP) investigators.

\section{Disclosure}

The authors report no conflicts of interest in this work.

\section{References}

1. Swanson LM, Hamilton JC, Feldman MD. Physician-based estimates of medically unexplained symptoms: a comparison of four case definitions. Fam Pract. 2010;27(5):487-493.

2. van Eck van der Sluijs JF, ten Have M, Rijnders C, van Marwijk H, de Graaf R, van der Feltz-Cornelis CM. Medically (un)explained symptoms in the general population: association with prevalent and incident mental disorders. PLoS One. 2014;10(4):e0123274. 
3. Henningsen P, Zimmermann T, Sattel H. Medically unexplained physical symptoms, anxiety, and depression: a meta-analytic review. Psychosom Med. 2003;65(4):528-533.

4. Walker EA, Keegan D, Gardner G, Sullivan M, Katon WJ, Bernstein D. Psychosocial factors in fibromyalgia compared with rheumatoid arthritis: I. Psychiatric diagnoses and functional disability. Psychosom Med. 1997;59(6):565-571.

5. Escobar JI, Cook B, Chen CN, et al. Whether medically unexplained or not, three or more concurrent somatic symptoms predict psychopathology and service use in community populations. J Psychosom Res. 2010;69(1):1-8.

6. Jackson JL, Kroenke K. Difficult patient encounters in the ambulatory clinic: clinical predictors and outcomes. Arch Intern Med. 1999;159(10): 1069-1075.

7. van der Feltz-Cornelis CM, ten Have M, Penninx BW, Beekman AT, Smit JH, de Graaf R. Presence of comorbid somatic disorders among patients referred to mental health care in the Netherlands. Psychiatr Serv. 2010;61(11):1119-1125.

8. Reid S, Wessely S, Crayford T, Hotopf M. Frequent attenders with medically unexplained symptoms: service use and costs in secondary care. Br J Psychiatry. 2002;180:248-253.

9. van der Feltz-Cornelis CM, van Oppen P, Adèr HJ, van Dyck R. Randomised controlled trial of a collaborative care model with psychiatric consultation for persistent medically unexplained symptoms in general practice. Psychother Psychosom. 2006;75(5):282-289.

10. Verhaak PF, Tijhuis MA. The somatizing patient in general practice. Int J Psychiatr Med. 1994;24(2):157-177.

11. van der Feltz-Cornelis CM, Meeuwissen JA, De Jong FJ, Hoedeman R, Elfeddali I. Randomised controlled trial of a psychiatric consultation model for treatment of common mental disorder in the occupational health setting. BMC Health Serv Res. 2007; 7:29.

12. ten Have M, Oldehinkel A, Vollebergh W, Ormel J. Does neuroticism explain variations in care service use for mental health problems in the general population? Results from the Netherlands Mental Health Survey and Incidence Study (NEMESIS). Soc Psychiatry Psychiatr Epidemiol. 2005;40(6):425-431.

13. von Elm E, Altman DG, Egger M, et al. The strengthening the reporting of observational studies in epidemiology (STROBE) statement: guidelines for reporting observational studies. J Clin Epidemiol. 2008;61(4): 344-349.

14. de Graaf R, Ten Have M, van Dorsselaer S. The Netherlands mental health survey and incidence study-2 (NEMESIS-2): design and methods. Int J Methods Psychiatr Res. 2010;19(3):125-141.

15. de Graaf R, ten Have M, van Gool C, van Dorsselaer S. Prevalence of mental disorders and trends from 1996 to 2009. Results from the Netherlands mental health survey and incidence study-2. Soc Psychiatry Psychiatr Epidemiol. 2012;47(2):203-213.

16. Rosendal M, Fink P, Falkoe E, Schou Hansen H, Olesen F. Improving the classification of medically unexplained symptoms in primary care. Eur J Psychiat. 2007;21:25-36.

17. Brazier JE, Harper R, Jones NM, et al. Validating the SF-36 health survey questionnaire: new outcome measure for primary care. BMJ. 1992; 305(6846):160-164.

18. Aaronson NK, Muller M, Cohen PD, et al. Translation, validation, and norming of the Dutch language version of the SF-36 health survey in community and chronic disease populations. J Clin Epidemiol. 1998; 51(11):1055-1068.

19. American Psychiatric Association. Diagnostic and Statistical Manual of Mental Disorders. 4th ed. Arlington, VA: APA; 2000. [text revision].

20. American Psychiatric Association. Diagnostic and Statistical Manual of Mental Disorders. 5th ed. Arlington, VA: American Psychiatric Publishing; 2013.

21. Guthrie E, Thompson D. Abdominal pain and functional gastrointestinal disorders. BMJ. 2002;325(7366):701-703.

22. Mayou R, Farmer A. ABC of psychological medicine: functional somatic symptoms and syndromes. BMJ. 2002;325(7358):265.
23. Thompson WG, Longstreth GF, Drossman DA, Heaton KW, Irvine EJ, Müller-Lissner SA. Functional bowel disorders and functional abdominal pain. Gut. 1999;45(suppl II):II43-II47.

24. Deyo RA, Rainville J, Kent DL. What can the history and physical examination tell us about low back pain? JAMA. 1992;268(6): 760-765.

25. Central Bureau of Statitics (CBS). Netherlands Central Bureau of Statistics (CBS) list. CBS vademecum 2005. Den Haag: CBS; 2005.

26. de Graaf R, Ten Have M, Tuithof M, van Dorsselaer S. First-incidence of DSM-IV mood, anxiety and substance use disorders and its determinants: results from the Netherlands mental health survey and incidence study-2. J Affect Disord. 2013;149(1-3):100-107.

27. Baker MM, Stabile M, Deri C. What Do Self-Reported, Objective Measures of Health Measure? NBER Working Paper Series. Cambridge, MA: NBER; 2001.

28. Knight M, Stewart-Brown S, Fletcher L. Estimating health needs: the impact of a checklist of conditions and quality of life measurement on health information derived from community surveys. J Public Health Med. 2001;23(3):179-186.

29. National Center for Health Statistics. Evaluation of national health interview survey diagnostic reporting. Series 2: Data Evaluation and Methods Research. Vital Health Stat 2. 1994;2(120):1-116.

30. Alonso J, Angermeyer MC, Bernert S, et al. Sampling and methods of the European study of the epidemiology of mental disorders (ESEMeD) project. Acta Psychiatr Scand Suppl. 2004;420(109):8-20.

31. De Graaf R, Ormel J, Ten Have M. Mental disorders and service use in the Netherlands. Results from the European Study of the Epidemiology of Mental Disorders (ESEMeD). In: Kessler RC, Üstün TB, editors. The WHO World Mental Health Surveys. Global Perspectives on the Epidemiology of Mental Disorders. New York, NY: Cambridge University Press; 2008:388-405.

32. Haro JM, Arbabzadeh-Bouchez S, Brugha TS, et al. Concordance of the composite international diagnostic interview version 3.0 (CIDI 3.0) with standardized clinical assessments in the WHO world mental health surveys. Int J Methods Psychiatr Res. 2006;15(4):167-180.

33. Andrews G, Peters L. The psychometric properties of the composite international diagnostic interview. Soc Psychiatry Psychiatr Epidemiol. 1998;33(2):80-88

34. Wittchen HU. Reliability and validity studies of the WHO - composite international diagnostic interview (CIDI): a critical review. J Psychiatr Res. 1994;28(1):57-84.

35. Skinner CJ, Holt D, Smith TMF. Analysis of Complex Surveys. Chichester: Wiley; 1989.

36. Kroenke K. Patients presenting with somatic complaints: epidemiology, psychiatric co-morbidity and management. Int JMethods Psychiatr Res. 2003;12(1):34-43.

37. Toussaint A, Murray AM, Voigt K, et al. Development and validation of a new self-report measure: the 'somatic symptom disorder - B criteria scale (SSD-12)'. J Psychosom Res. 2015;78(6):627.

38. Nimnuan C, Hotopf M, Wessely S. Medically unexplained symptoms, an epidemiological study in seven specialities. J Psychosom Res. 2001; 51(1):361-367.

39. Kroenke K. Efficacy of treatment for somatoform disorders: a review of randomized controlled trials. Psychosom Med. 2007;69(9): 881-888.

40. van der Feltz-Cornelis CM, Hoedeman R, Keuter EJ, Swinkels JA. Presentation of the multidisciplinary guideline medically unexplained physical symptoms (MUPS) and somatoform disorder in the Netherlands: disease management according to risk profiles. J Psychosom Res. 2012;72(2):168-169.

41. van Dessel N, den Boeft M, van der Wouden JC, et al. Non-pharmacological interventions for somatoform disorders and medically unexplained physical symptoms (MUPS) in adults (Review). Cochrane Database Syst Rev. 2014;(11):CD011142.

42. Budtz-Lilly A, Vestergaard M, Fink P, Carlsen AH, Rosendal M. Patient characteristics and frequency of bodily distress syndrome in primary care: a cross-sectional study. Br J Gen Pract. 2015;65(638): e617-e623. 
43. Winkler P, Horácek J, Weissová A, Šustr M, Brunovský M. Physical comorbidities in depression co-occurring with anxiety: a cross sectional study in the Czech primary care system. Int J Environ Res Public Health. 2015;12(12):15728-15738.

44. de Heer EW, Gerrits MM, Beekman AT, et al. The association of depression and anxiety with pain: a study from NESDA. PLoS One. 2014;9(10):e106907.

45. Gerrits MM, van Marwijk HW, van Oppen P, van der Horst $H$, Penninx BW. Longitudinal association between pain, and depression and anxiety over four years. J Psychosom Res. 2015;78(1):64-70.

46. Mykletun A, Bjerkeset O, Overland S, Prince M, Dewey M, Stewart R. Levels of anxiety and depression as predictors of mortality: the HUNT study. Br J Psychiatry. 2009;195(2):118-125.

47. Lamb J, Bower P, Rogers A, Dowrick C, Gask L. Access to mental health in primary care: a qualitative meta-synthesis of evidence from the experience of people from 'hard to reach' groups. Health (London). 2012;16(1):76-104.

48. Steinmetz D, Tabenkin $H$. The 'difficult patient' as perceived by family physicians. Fam Pract. 2001;18(5):495-500.

49. van Dessel N, Leone SS, van der Wouden JC, Dekker J, van der Horst HE. The PROSPECTS study: design of a prospective cohort study on prognosis and perpetuating factors of medically unexplained physical symptoms (MUPS). J Psychosom Res. 2014;76(3):200-206.
50. van der Feltz-Cornelis CM, van Os TW, van Marwijk HW, Leentjens AF. Effect of psychiatric consultation models in primary care. A systematic review and meta-analysis of randomized clinical trials. J Psychosom Res. 2010;68(6):521-533.

51. Leentjens AF, Boenink AD, Sno HN, et al. The guideline "consultation psychiatry" of the Netherlands Psychiatric Association. J Psychosom Res. 2009;66(6):531-535.

52. Ofman JJ, Badamgarav E, Henning JM, et al. Does disease management improve clinical and economic outcomes in patients with chronic diseases? A systematic review. Am J Med. 2004;117(3):182-192.

53. Roberts RG, Gask L, Arndt B, et al. Depression and diabetes: the role and impact of models of health care systems. J Affect Disord. 2012; 142(suppl):S80-S88.

54. de Heer EW, Dekker J, van Eck van der Sluijs JF, et al. Effectiveness and cost-effectiveness of transmural collaborative care with consultation letter (TCCCL) and duloxetine for major depressive disorder (MDD) and (sub)chronic pain in collaboration with primary care: a randomized placebo-controlled multi-Centre trial. TCC:PAINDIP. BMC Psychiatry. 2013;13(1):147.

55. Katon WJ, Lin EH, Von Korff M, et al. Collaborative care for patients with depression and chronic illnesses. N Engl J Med. 2010;363(27): 2611-2620.
Neuropsychiatric Disease and Treatment

\section{Publish your work in this journal}

Neuropsychiatric Disease and Treatment is an international, peerreviewed journal of clinical therapeutics and pharmacology focusing on concise rapid reporting of clinical or pre-clinical studies on a range of neuropsychiatric and neurological disorders. This journal is indexed on PubMed Central, the 'PsycINFO' database and CAS,

\section{Dovepress}

and is the official journal of The International Neuropsychiatric Association (INA). The manuscript management system is completely online and includes a very quick and fair peer-review system, which is all easy to use. Visit http://www.dovepress.com/testimonials.php to read real quotes from published authors. 